\title{
Split cord malformation (SCM) associated with tight filum terminale: A case report
}

\author{
Iraj Lotfinia ${ }^{1 *}$ and Taghi Imani ${ }^{2}$ \\ ${ }^{1}$ Professor of Neurosurgery, Tabriz University of Medical Science, Tabriz, Iran \\ ${ }^{2}$ Resident of Neurosurgery, Tabriz University of Medical Science, Tabriz, Iran
}

\begin{abstract}
Diastematomyelia, a type of occult spinal dysraphism, is a congenital disorder which is usually diagnosed in childhood. However, some patients may experience the clinical symptoms for the first time in adulthood. Likewise, tight filum terminale is a slight abnormality of the spinal cord often appearing in children. Co-occurrence of both lesions in an adult is rare. This case report pertains to a patient with both diastematomyelia and tight filum terminale. The symptoms of the latter emerged after the patient had undergone surgery for diastematomyelia.
\end{abstract}

\section{Introduction}

Diastematomyelia is a rare form of spinal dysraphism [1-9] characterized by a sagittal cleft of varying extents splitting the spinal cord, conus medullaris, or filum terminale [1].

Symptoms often develop in patients due to an osseous septum dividing the spinal cord into two lateral halves [10]. Patients with "split cord malformation" (SCM) may have tethering from multiple causes such as myelomeningocele, intradural lipoma or fatty filum, associated with their congenital anomaly [11]. It is critical to consider the significance of the association between SCMs and other spinal cord tethering lesions prior to surgery [12].

One of the malformations reported along with SCMs is tethered cord due to tight filum terminale. Both malformations are common in childhood $[2,13,14]$ and their misdiagnosis may lead to complications most of which requiring reoperation. In this paper we present an adult patient with SCM in whom symptoms of tight filum terminale appeared after surgery.

\section{Case report}

Our patient was a 39-year-old female with the chief complaint of back pain radiating to the gluteal area on both sides and to the left inguinal region. The pain had started a year ago without any precedence. The patient complained of numbness in the lower extremities and reported experiencing exhaustion and weakness in the lower extremities after few minutes of walking. No significant past medical history or drug history could be obtained. On physical examination, the patient was found to have hair patch over the lumbar area (Figure 1a). No neurologic deficit or sensory level was detected. Laseque, cross Laseque and Reverse Laseque tests were negative. On the basis of skin lesion and neurologic symptoms, the diagnosis of Diastematomyelia was made which was later confirmed by the CT and MRI images (Figure 1b). The images of CT scan revealed diastematomyelia and bone spurs originating from the posterior element and extending anteriorly (Figure 1b). The MRI images showed diastematomyelia along with a split spinal cord (Figure 1c). The length of the split spinal cord was considerable as revealed by the MRI myelography (Figure 1d) and the lower end of the spinal cord reached down to L4-L5 (Figure 1e). Given the clinical symptoms of the patient and the existence of diastematomyelia along with a bone septum, surgery was advised. Surgery included laminectomy of the entire L3 and part of L4, with the whole bone septum being removed. The dura mater was opened and adhesions and the thick arachnoid tissues between the two spinal cords were released. The junction between conus medullaris and filum terminale was not discernible and

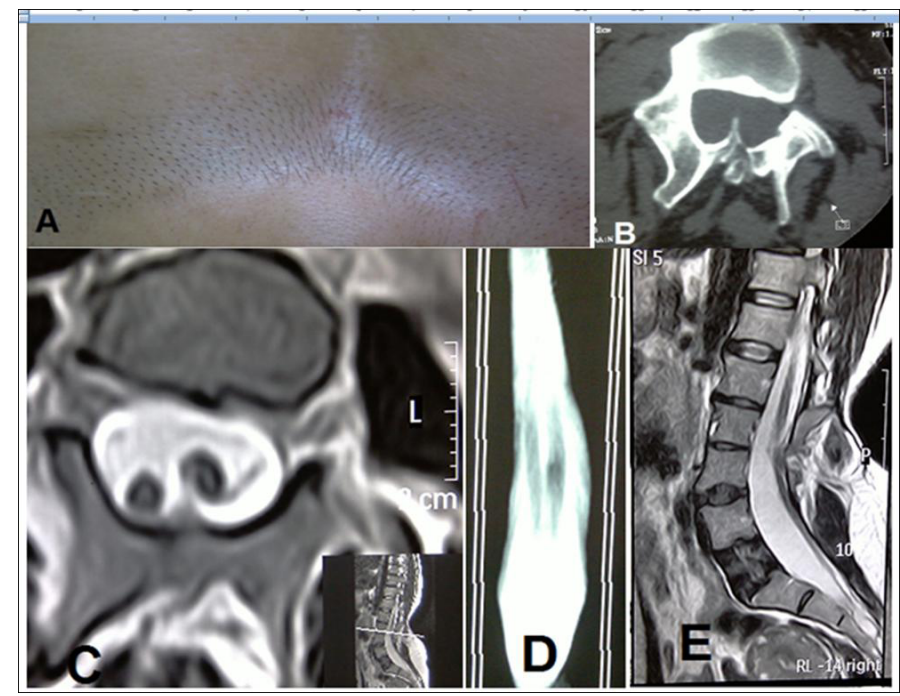

Figure 1. A) The presence of hirsutism in the lumbar region B) The presence of bone spurs originating from posterior elements C) T2 MRI showing the split spinal cord D) MRI myelography showing the length of the spinal cord split E) T2 MRI showing the lower limit of the conus medularis between the L4-L5.

Correspondence to: Iraj Lotfinia, Professor of Neurosurgery, Tabriz University of Medical Science, Tabriz, Iran, Tel: 09141145738; E-mail: Lotfinai@yahoo.com

Key words: diastematomyelia, tight filum terminale, occult spinal dysraphism

Received: July 02, 2016; Accepted: July 22, 2016; Published: July 26, 2016 
owing to the unavailability of electrophysiological tests, the filum could not be dissected. Next, the dura mater sheath around the septum was also removed and the anterior part of the dura mater was left intact while the posterior part was repaired.

During surgery, except for relatively severe bleeding from the area surrounding the septum which was controlled by bipolar, surgicel and bone wax, no other significant problem was encountered. Finally, an epidural drain was placed and the layers were sutured anatomically. The evening following surgery and on the next morning, the patient expressed feeling comfortable and neurological examination revealed no problems. Drain secretions being slight, the drain was removed. On the afternoon of the second day after surgery, the patient reported paraesthesia in the legs and by night weakness had set in which became progressive and by the next morning the patient had became paraplegic. In view of the epidural bleeding during surgery as well as the patient's symptoms, the possibility of epidural hematoma was considered and an immediate MRI was performed. However, apart from the changes frequently observed after surgery, the MRI did not reveal any hematoma and failed to provide useful diagnostic information (Figure 2a). On reexamination of the patient's pre-operative MRI which had indicated a thickened filum (Figure $2 b$ ) attached to the dorsal part of the dural sac (Figure 2c), the possibility of tight filum terminale was suspected and an emergency operation was performed on the patient. In the second surgery, partial laminectomy of S1 was performed, the durameter opened and the distal end of the filum terminale was dissected.

The symptoms of the patient subsided immediately after the surgery and no complications emerged in the next 48 hours. At follow up after 6 months, the patient reported no problems.

\section{Discussion}

Being rarely reported in adults, SCM is a form of closed neural tube defect in which the spinal cord is longitudinally split by a fibrous band or a bone spicule [11]. Various terms have been used to address these malformations and several authors have tried to distinguish between diplomyelia (doubled spinal cord) and diastematomyelia (split spinal cord). The former is defined as two cords lying in one dural space, without an intervening septum and the latter is defined as two cords being housed within individual thecal sacs separated by an

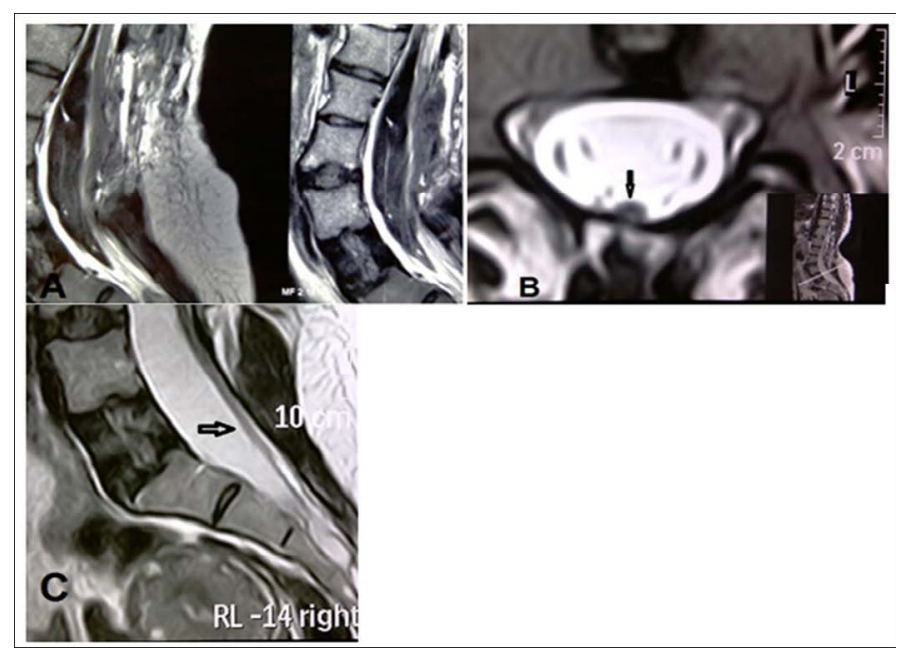

Figure 2. A) Post surgery MRI ruling out a hematoma in the operated area B) Axia view MRI prior to surgery (the arrow) revealing a thickened filum terminale close to the posterior wall of the durameter C) Saggital view MRI prior to surgery (the arrow) revealing a thickened filum terminale close to the posterior wall of the durameter. osteofibrotic septum with each cord having paramedian roots. In this report, the authors used the term 'split cord malformation' (SCM) to avoid a semantic discussion. Split cord malformations are commonly divided into two types. Type I, the more common type, consists of two hemicords, each with its own dural sheath separated by a rigid osseocartilaginous septum. Type II has two hemicords housed in a common dural sheath separated by a non-rigid fibrous septum [2].

The location of the lesion can occur at any level along the spine, but is most frequently seen in the lower thoracic or upper lumbar spine $[2,9,13]$. It is also three times more common in female than male patients [15]. Most patients with this condition present during childhood and only a few cases have been documented in the adult population $[13,16,17]$. The mean age at the time of diagnosis is 5 years and the presenting symptoms in adulthood differ from those in childhood [13]. In adults, the common presentations are lumbar radiculopathy and myelopathy. Other presenting symptoms include sensory and motor deficits, skeletal and foot deformities, and bladder and bowel disturbances [15]. An important feature of SCM is its frequent association with secondary spinal anomalies [12]. SCM may be isolated [2] or associated with a large number of anomalies [9] it may be associated with abnormalities arising from various ectodermal or endodermal remnants such as congenital scoliosis [18], spondylolisthesis [19], spina bifida, kyphoscoliosis, butterfly vertebrae, hemivertebrae, a dermal sinus tract, and tethering of the spinal cord with lipoma, teratoma, dermoids, neurenteric cysts [2]. In a review of Proctor et al. out of 16 patients, 11 (69\%) harbored a second lesion, with fatty or tight filum being the most common (6 patients) [12]. SCM and fatty filum are completely different clinical entities and thought to arise via different pathophysiologies, the diagnosis of which in the same patient is important for appropriate management [11]. During gasterogenesis, the formation of the spinal cord occurs in several stages. Neurulation gives rise to the spinal cord only down to the lumbar spine region. The spinal cord caudal to this is formed by the process of canalization. Errors during neurulation may lead to various congenital malformations such as myelomeningocele, meningocele, lipomyelomeningocele, SCMs, the dermal sinus, and intraspinal tumors such as dermoids and epidermoids [20]. Pang and coworkers $[21,22]$ postulated that the participation of certain meningeal precursor cells within an errant midline ectoendodermal adhesion tract during

early gastrulation determines how SCMs can be classified into two radically different types [22]. If the tract also contains cells of meningeal precursor cells, the resultant malformation would be SCM Type I. Otherwise, the formation of a separate dural sleeve and bone septum does not occur, and the malformation would be Type II [23]. The tail bud forms after completion of neurulation. The formation of the neural tube caudal to that formed during neurulation occurs by canalization of the tail bud, which occurs during stages 13 through 20 (days 28-48) [24]. This process consists of the development of vacuoles within the tail bud, that later coalesce to form the canal, which connects with the rostral neural tube formed earlier during neurulation. Abnormalities that develop during canalization of the tail bud can give rise to the thick terminal filum, terminal myelocystocele, and lipomyelomeningocele [20]. The onset of the symptomatic tethered cord syndrome (TCS) in combination with diastematomyelia during adulthood is rare $[20,25]$.

In most patients with SCM, conus lie lower than normal and the incidence of low-lying cord is also said to be as high as $83 \%$ of the patients [15]. Distinguishing between low-lying conous due to sole diastematomyelia and that due to diastematomyelia along with tight filum terminale, especially in cases with no fat tissue inside the filum, 
may be difficult. Diastematomyelia is often associated with a thickened or fatty filum [15]. According to the reports, in $40 \%$ of these patients filum terminale is short and thickened [26]. Hence, in patients affected by SCMs, abnormality of the filum terminale cannot be indicative of a tethered cord due to tight filum terminale. TCS due to tight filum terminale is usually diagnosed in childhood and its onset in adult life is uncommon $[14,27,28]$. Thickness of the filum terminale greater than 2 $\mathrm{mm}$ is considered abnormal in children. Although controversial [29], radiographic criteria for TCS alone are inadequate for the diagnosis of TCS and must be combined with the clinical presentation to establish the diagnosis [30].

Two main factors, i.e., local distraction and vascular compromise, contribute to the pathophysiology of TCS [31]. If detethering of the cord is performed within 2-8 weeks of the initial insult, blood flow and spinal evoked potentials may return to normal as longer delays may result in irreversible changes [31]. All patients with SCM are believed to be surgically treated prophylactically even asymptomatic $[7,15,26,32]$. However, the role of prophylactic surgery in SCM in asymptomatic adults is yet controversial [13]. Nevertheless, while there is no doubt that for patients with clinical symptoms surgery is indicated, there is no consensus as regards the dissection of filum following diastomatomyelia surgery. Numerous hypotheses have been proposed on the dissection of the filum terminale following the surgery of SCMs. In the study of Venkataramana [26] and Mahapatra [9], the filum was also excised in all patients. In 12 patients reported by Leung et al. [31] only two patients underwent filum resection. According to Zachary et al. [33], most authors advocate sectioning of a normal filum in all patients with a low-lying conus; however, in connection with diastematomyelia surgery $[34,35]$. Have made no mention of the necessity to section filum terminale.

\section{Conclusion}

Although in our patient, the clinical symptoms were primarily related to the tethered cord, in patients with split cord, the probability of tethered cord due to tight filum terminale should be considered. Progressive exacerbation of neurological symptoms following diastematomyelia surgery points to the possibility of a tethered cord due to other causes, particularly tight filum terminale. In these patients, sectioning filum terminale would prevent exacerbation of the symptoms and obviate the need for reoperation. That is, an easily visible and accessible filum terminale during diastematomyelia surgery is an indication for its sectioning.

\section{References}

1. Sami H, Ross E, Walter M, Goli S (2003) Split spinal cord (diastematomyelia). Neurology 60: 491. [Crossref]

2. Hung PC, Wang HS, Lui TN, Wong AM (2010) Sonographic findings in a neonate with diastematomyelia and a tethered spinal cord. J Ultrasound Med 29: 1357-1360. [Crossref]

3. Moriya J, Kakeda S, Korogi Y, Soejima Y, Urasaki E, et al. (2006) An unusual case of split cord malformation. AJNR Am J Neuroradiol 27: 1562-1564. [Crossref]

4. Sepulveda W, Kyle PM, Hassan J, Weiner E (1997) Prenatal diagnosis of diastematomyelia: case reports and review of the literature. Prenat Diagn 17: 161-165. [Crossref]

5. Drake JM (2007) Surgical management of the tethered spinal cord--walking the fine line. Neurosurg Focus 23: E4. [Crossref]

6. Cheng B, Li FT, Lin L (2012) Diastematomyelia: a retrospective review of 138 patients. J Bone Joint Surg Br 94: 365-372. [Crossref]

7. Sinha S, Agarwal D, Mahapatra AK (2006) Split cord malformations: an experience of 203 cases. Childs Nerv Syst 22: 3-7. [Crossref]
8. Khandelwal A, Tandon V, Mahapatra A (2011) An unusual case of 4 level spinal dysraphism: multiple composite type 1 and type 2 split cord malformation, dorsal myelocystocele and hydrocephalous. J Pediatr Neurosci 6: 57-61. [Crossref]

9. Mahapatra AK (2011) Split cord malformation - A study of 300 cases at AIIMS 19902006. J Pediatr Neurosci 6: S41-45. [Crossref]

10. Yamada S, Won DJ, Pezeshkpour G, Yamada BS, Yamada SM, et al. (2007) Pathophysiology of tethered cord syndrome and similar complex disorders. Neurosurg Focus 23: E6. [Crossref]

11. Izci Y, Pusat S, Onguru O (2011) Fatty filum with different histological features. Case report. Neurocirugia (Astur) 22: 457-460. [Crossref]

12. Proctor M, Scott M (2000) Long-term outcome for patients with split cord malformation Neurosurg Focus 10: 5. [Crossref]

13. Kumar DS, Concepcion LA (2007) Adult with progressive foot deformity. Br J Radiol 80: 384-387. [Crossref]

14. Venkataramana NK (2011) Spinal dysraphism. J Pediatr Neurosci 6: S31-40. [Crossref]

15. Gan YC, Sgouros S, Walsh AR, Hockley AD (2007) Diastematomyelia in children treatment outcome and natural history of associated syringomyelia. Childs Nerv Syst 23: 515-519. [Crossref]

16. Kaminker R, Fabry J, Midha R, Finkelstein JA (2000) Split cord malformation with diastematomyelia presenting as neurogenic claudication in an adult: a case report. Spine (Phila Pa 1976) 25: 2269-2271. [Crossref]

17. Uzüm N, Dursun A, Baykaner K, Kurt G (2005) Split-cord malformation and tethered cord associated with immature teratoma. Childs Nerv Syst 21: 77-80. [Crossref]

18. Qureshi MA, Asad A, Pasha IF, Malik AS, Arlet V (2009) Staged corrective surgery for complex congenital scoliosis and split cord malformation. Eur Spine J 18: 1249-1254. [Crossref]

19. König M, Boszczyk B (2012) Limited access surgery for 360 degrees in-situ fusion in a dysraphic patient with high-grade spondylolisthesis. Eur Spine J 21: 390-5. [Crossref]

20. Warder DE (2001) Tethered cord syndrome and occult spinal dysraphism. Neurosurg Focus 10: e1. [Crossref]

21. van Aalst J, Beuls EA, Vles JS, Cornips EM, van Straaten HW (2005) The intermediate type split cord malformation: hypothesis and case report. Childs Nerv Syst 21: 10201024. [Crossref]

22. Pang D (2001) Ventral tethering in split cord malformation. Neurosurg Focus 10: e6. [Crossref]

23. Proctor MR, Bauer SB, Scott RM (2000) The effect of surgery for split spinal cord malformation on neurologic and urologic function. Pediatr Neurosurg 32: 13-19. [Crossref]

24. Hsieh P, tapleton C, Moldavskiy P, Koski T, Ondra S, et al. (2010) Posterior vertebral column subtraction osteotomy for the treatment of tethered cord syndrome: review of the literature and clinical outcomes of all cases reported to date. Neurosurg Focus 29: E6. [Crossref]

25. Pang D, Wilberger JE Jr (1982) Tethered cord syndrome in adults. J Neurosurg 57 32-47. [Crossref]

26. Venkataramana N (2006) Split cord malformation. J Pediatr Neurosci 6: 5-9.

27. Kaptanog lu E, Beskonakli E, Okutan M, Taskin Y (2003) Tethered Spinal Cord, Diastematomyelia, and Terminal Syringomyelia in an Adult. Turkish Neurosurgery 13: $42-46$.

28. Umur AS, Selcuki M, Selcuki D, Bedük A, Doganay L (2008) Adult tethered cord syndrome mimicking lumbar disc disease. Childs Nerv Syst 24: 841-844. [Crossref]

29. Hertzler DA 2nd, DePowell JJ, Stevenson CB, Mangano FT (2010) Tethered cord syndrome: a review of the literature from embryology to adult presentation. Neurosurg Focus 29: E1. [Crossref]

30. Filippidis AS, Kalani MY, Theodore N, Rekate HL (2010) Spinal cord traction, vascular compromise, hypoxia, and metabolic derangements in the pathophysiology of tethered cord syndrome. Neurosurg Focus 29: E9. [Crossref]

31. Leung YL, Buxton N (2005) Combined diastematomyelia and hemivertebra: a review of the management at a single centre. J Bone Joint Surg Br 87: 1380-1384. [Crossref]

32. Lotfinia I, Sayyahmelli S ,Kosroshahi MT, Vahedi N, Golzari S (2014) Skin Lesions in Occult Spinal Dysraphism: A Case Series. Neurosurgery Quarterly 24: 63-66. 
33. Zachary N, Litvack, Nathan RS (2011) Split Spinal Cord. In: Youmans Neurological Surgery (Elsevier Saunders), (6 $6^{\text {th }}$ edn), 2219-2226.

34. Conley A, Tye G, Ward J, Myseros J (2012) Occult spinal dysraphism and the tethered spinal cord. In: Spine surgery techniques, complications avidance, and the management (Elsevier Saunders) (3 ${ }^{\text {rdedn }), ~ 1141-1154 . ~}$

35. Shah M, Santiago P (2011) Congenital Abnormalities of the Thoracic and Lumba Spine. In: Youmans Neurological Surgery (Elsevier Saunders) (6 $\left.6^{\text {th }} \mathrm{edn}\right), 2973-2978$.

Copyright: (C2016 Lotfinia I. This is an open-access article distributed under the terms of the Creative Commons Attribution License, which permits unrestricted use, distribution, and reproduction in any medium, provided the original author and source are credited. 